\title{
Mobile Money, Financial Inclusion and Digital Payment: The Case of Vietnam
}

\author{
Tran Hung Son ${ }^{1}$, Nguyen Thanh Liem ${ }^{1} \&$ Nguyen Vinh Khuong ${ }^{2}$ \\ ${ }^{1}$ Center for Economic and Financial Research, University of Economics and Law, VNU-HCM, Ho Chi Minh City, \\ Vietnam \\ ${ }^{2}$ Faculty of Accounting and Auditing, University of Economics and Law, VNU-HCM, Ho Chi Minh City, Vietnam \\ Correspondence: Tran Hung Son, Center for Economic and Financial Research, University of Economics and Law, \\ VNU-HCM, Ho Chi Minh City, Vietnam.
}

Received: October 28, 2019

Accepted: November 23, 2019

Online Published: December 4, 2019

doi:10.5430/ijfr.v11n1p417

URL: https://doi.org/10.5430/ijfr.v11n1p417

\begin{abstract}
The study provides an overview of mobile money account usage, financial inclusion and digital payment transaction trends in Vietnam, and considers the factors influencing these trends. In general, the rates of using mobile money service and account ownership at financial intermediaries in Vietnam are still low, and other indicators of digital transactions suggest low levels compared to those of countries with low- and middle- income as well as to the world averages. The research also shows that owning an account at a financial intermediary facilitates the use of mobile money. This is a positive trend, at least compared to the situation in some African countries. Finally, having an account at a financial intermediary and using mobile money services generally have a positive effect on the participation in non-cash transactions.
\end{abstract}

Keywords: mobile money, digital payment transactions, financial inclusion

JEL: G20, G28

\section{Introduction}

In recent years, developing an inclusive financial system serving all members of society has become an important policy in many countries, especially emerging economies. Financial inclusion (FI) is the provision of appropriate and convenient financial services for individuals, households and businesses. Notably, mobile devices have played an important role in promoting inclusive finance in developing countries (Kanobe, Alexander, \& Bwalya, 2017). Thanks to being highly mobile, ubiquitously available and personalized, mobile phones have quickly spread not only in developed countries but also in most developing countries, overcoming geographical barriers. According to GSMA (2015), in the last decade, mobile money has helped expand financial services more than what traditional banks did in the last century. The GSMA report also found that at least 19 countries had more mobile money accounts than bank accounts and 37 countries had 10 times more mobile money agents than bank branches.

In Vietnam, since 2016, the State Bank has cooperated with World Bank experts to develop a national financial inclusion strategy. Having a large population with low financial literacy, Vietnam is among the 25 countries priortizing to focus on financial inclusion (FI) efforts from the Universal Access to Finance (UFA) initiative in 2020. The goal of this initiative is to help people who are not currently using banking services have access to the formal financial system. Assisting an adult to open a trading account is the first step towards FI. People can then use the services they need such as savings, payments, loans and insurance. Bringing formal financial services to millions of people who currently have little or no use of financial services will help Vietnam achieve both its goals of poverty reduction and economic growth, helping the country to achieve its stated goals in Vietnam 2035 report.

At the 2019 Plan Implementation Conference of the Ministry of Information and Communications, the Prime Minister agreed to allow a pilot use of a telecom account for payment, which will have a strong impact on non-cash payments, promote trade and safety and reduce costs, cash circulation and other means of payment within and outside the banking system. This is also the main basis for mobile money to thrive and play an important role in promoting financial inclusion in Vietnam. 
In this very context, to promote and facilitate mobile money in Vietnam, there is a need for an empirical study that provides evidence on the link between mobile money and financial inclusion and digital payment transaction trends in Vietnam. The current study makes a major contribution in this sense. The objective of this study is to analyze the factors affecting individuals' use of mobile money service in Vietnam employing World Bank's Global Findex data (2018). In addition, the study also analyzes the nexus between the use of mobile money and financial inclusion and digital payment activities in Vietnam.

Logit regression with robust standard errors is used to estimate the determinants of the likelihood to use mobile money services and have accounts at financial intermediaries, and the impact of mobile money and having an account at a financial intermediary on the ability to use digital transactions. The results reveal that mobile money and financial intermediation accounts are not mutually exclusive, but complementary. Besides, mobile money accounts and financial intermediaries generally have a positive effect on the trend of non-cash transactions in Vietnam.

\section{Previous Studies on the Relationship Between Mobile Money, Digital Payment Transactions and Financial Inclusion}

Financial exclusion is a pervasive problem in developing countries: while bank account ownership is quite popular in high-income OECD countries, roughly half of adults in developing countries have bank accounts (Demirguc-Kunt et al, 2015). The significant disparities between developed and developing countries are due to the fact that financial service providers are unable to expand their reach to the poor at an affordable expense, for it is costly to set up and operate bank branches. However, the advent of mobile technology is revolutionizing access to financial services by changing the way people send/receive money, save, borrow and manage risk. Indeed, one area in which mobile phone penetration has impacted economic growth is by expanding mobile financial services to those who are financially excluded (Andrianaivo \& Kpodar, 2012).

Mobile financial services (MFS) involve the use of mobile phones to access financial services. MFS has been considered as an innovative and effective means of inclusive financial development by providing financial services to people who do not have access to banking services (Sihvonen, 2006). MFS includes a variety of financial services such as mobile payment, domestic and international money transfers. Mobile banking is a service that provides customers with a channel to interact with the bank via mobile devices (Barnes \& Corbitt, 2003). On the other hand, mobile payments involve the use of mobile devices to pay for goods or services at point of sale or remote locations (KPMG, 2011) and are increasingly used in developed countries. Mobile money transfers, like the case of $\mathrm{m}$ - Pesa in Kenya, are common in developing countries where users are reducing access to bank accounts but there is a high demand for sending and receiving money in the community. Remittance operations involve international remittance, often used by migrant workers who send money back to their home countries. Today, traditional money transfer service providers are subject to competition from telecom providers with advanced technology and lower service costs (Merritt, 2011).

The importance of mobile technology in expanding financial services to the poor at an affordable cost is due to the initial investment and other fixed costs, so the marginal cost is very low for every transaction or for every new customer (Honohan and Beck, 2011). This has led to the rapid expansion of mobile money and MFS in developing countries, thereby promoting financial inclusion in these countries (Hinson, 2011; Maurer, 2012). These services have helped overcome infrastructure constraints and improve inclusive finance (Allen et al., 2014; Hinson, 2011; Maurer, 2012). Asongu et al. (2017) analyzed the use of mobile devices in African countries and showed that MFS has a positive impact on the financial development of these countries.

\section{Statistical Indicators on Mobile Money Accounts and Digital Payment Transactions in Vietnam}

The data used in this study cover indicators of mobile money accounts, financial institution accounts and digital payment transactions from the Global Findex data of the World bank (2018). In the dataset, (1) mobile money account is the proportion of individuals who have used mobile money service in the past 12 months; (2) account at a financial intermediary is the percentage of individuals who solely or jointly own accounts at banks or financial institutions such as credit cooperatives, microfinance institutions, etc., or own debit card; (3) digital payment transaction is the ratio of individuals using mobile money, credit or debit cards, or mobile phones to make payments from accounts, or using the internet to pay or buy online merchandise. This index also includes the percentage of individuals who pay bills, send and receive money, receive salaries, allowances ... via accounts at financial intermediaries or via mobile money accounts in the past 12 months.

Table 1 shows that the proportion of individuals owning accounts in financial intermediaries has increased from $21.4 \%$ in 2011 to 30\% in 2017 in Vietnam, which is still lower than that of low- and middle-income countries and the world average. 
Table 1. Ownership of accounts at financial intermediaries in Vietnam (\%)

\begin{tabular}{llll}
\hline Year & Vietnam & Low- \& middle-income countries & World Average \\
\hline 2017 & 30,0 & 56,1 & 67,1 \\
\hline 2014 & 30,9 & 40,6 & 61,2 \\
\hline 2011 & 21,4 & 28,9 & 50,6 \\
\hline
\end{tabular}

Source: The little data book on financial inclusion 2018

Regarding the rate of using mobile money service, although in Vietnam this rate has increased from $0.5 \%$ in 2014 to $3.5 \%$ in 2017 , this is still lower than other countries with low and middle income and also lower than the world average.

Table 2. Mobile money service usage rates in Vietnam (\%)

\begin{tabular}{llll}
\hline Year & Vietnam & Low- \& middle-income countries & World Average \\
\hline 2017 & 3,5 & 5,3 & 4,4 \\
\hline 2014 & 0,5 & 3,2 & 2,1 \\
\hline
\end{tabular}

Source: The little data book on financial inclusion 2018

For digital payment transactions, the percentage of these transactions in Vietnam is generally lower than the world average and countries with low and middle income levels (Table 3). However the proportions of transactions such as using accounts to receive wages from the private sector; using the internet to pay bills and buy things online; using mobile phone or internet to access accounts in Vietnam are higher than those of countries with low and middle income levels. This reflects the strong development of mobile networks and the Internet in Vietnam compared to countries with low and middle income levels, and also reflects the strong development trend of e-commerce. This is a very favorable basis for developing payment services through telecommunication accounts, as well as developing mobile money to promote inclusive finance in Vietnam.

Table 3. Share of digital transactions in Vietnam in $2017(\%)$

\begin{tabular}{|c|c|c|c|}
\hline & Vietnam & $\begin{array}{l}\text { Low- \& middle-income } \\
\text { countries }\end{array}$ & World average \\
\hline Make or receive digital payment & 22,7 & 29,2 & 52,3 \\
\hline Use account to pay bills & 2,9 & 7,5 & 22,3 \\
\hline Use accounts to receive wages from private sector & 8,9 & 5,5 & 15,9 \\
\hline Use accounts to receive governmental payments & 3,0 & 8,3 & 16,3 \\
\hline Use internet to pay bills and purchase goods online & 20,5 & 6,8 & 29,0 \\
\hline Use mobile devices/internet to access accounts & 9,2 & 8,3 & 24,9 \\
\hline Use debit or credit cards to purchase goods & 6,2 & 10,0 & 32,6 \\
\hline Send or receive money domestically through accounts & 9,6 & 10,1 & - \\
\hline
\end{tabular}

Source: The little data book on financial inclusion 2018

\section{Methodology}

\subsection{Determinants of Mobile Money}

The data used in this study cover indicators of mobile money accounts, financial institution accounts and digital payment transactions from the Global Findex data of the World bank. Logistic regression is employed in this study to evaluate several determinants of mobile money usage in Vietnam, and other models below. Logistic regression is used because the dependent variable is a dichotomous one, i.e. having only two possible outcomes. This approach is actually a special case of linear regression, and it helps predict the possibility of occurrence of an event through 
fitting data with a logit function. In this paper, we adopt Fanta et al. (2016)'s model to verify the determinants of mobile money in Vietnam:

$$
\text { account_mob }_{i}=\alpha_{0}+\alpha_{1} \text { account_fin }_{i}+\alpha_{2} X_{i}+\varepsilon_{i}
$$

Where account_mob ${ }_{i}$ denotes of using mobile money of an individual $i$, receiving the value of $i$ if the individual has mobile money account and 0 otherwise; account_fin ${ }_{\mathrm{i}}$ is the indicator of financial inclusion, receiving the value of 1 if the individual has accounts at financial intermediaries and zero otherwise; $\mathrm{X}_{\mathrm{i}}$ is a vector of control variables; and $\varepsilon_{\mathrm{i}}$ is the error term. The control variables include individual gender; age; educational level, income group; with a purpose to pay utility bills; borrow money from a financial institution; have received wages within the past 12 months.

\subsection{Effects of Mobile Money on Financial Inclusion}

To quantify the effect of mobile money on financial inclusion, the following equation is estimated:

$$
\text { account_fin }_{i}=\beta_{0}+\beta_{1} \text { account_mob }_{i}+\beta_{2} X_{i}+\eta_{i}
$$

Where account_fin $n_{i}$ is the indicator of financial inclusion, receiving the value of 1 if the individual has accounts at financial intermediaries and zero otherwise; account_mob ${ }_{i}$ denotes of using mobile money of an individual i, receiving the value of 1 if the individual has mobile money account and 0 otherwise; Other variables are defined the same as in equation (1) and $\eta_{\mathrm{i}}$ is the error term.

\subsection{Effects of Mobile Money and Financial Inclusion on Digital Payment Transactions}

To quantify the effect of mobile money and financial inclusion on digital payment transactions, the following model will be estimated:

$$
\text { digital_trans } s_{i}=\gamma_{0}+\gamma_{1} \text { account_fin }_{i}+\gamma_{2} \text { account_mob }_{i}+\gamma_{3} X_{i}+\omega_{i}
$$

Where Digital_trans $s_{i}$ is digital payment transactions such as: receive government transfers / remittances, receiving 1 if in cash and 0 otherwise; transfer money in cash, receiving 1 if money is not transferred in cash and 0 otherwise, debit_credit: whether the individual has a debit or credit card, 1 if yes, 0 if no; debit_credit_use: whether the individual has debit or credit card transactions, 1 if yes, 0 if no; delivery_int_cash: pay online, receiving 1 if payment is not in cash and 0 if otherwise ; billpaid_cash: pay utility bill, receiving 1 if pay bill by cash and 0 if otherwise; wage_cash: get salary, receiving 1 if in cash and 0 if otherwise ; account_fin $_{\mathrm{i}}$ is the indicator of financial inclusion, receiving the value of 1 if the individual has accounts at financial intermediaries and zero otherwise; account_mob ${ }_{i}$ denotes of using mobile money of an individual 1, receiving the value of 1 if the individual has mobile money account and 0 otherwise; Other variables are defined the same as in equation (1) and $\omega_{\mathrm{i}}$ is the error term.

\section{Results and Discussion}

This study uses Logit regression to estimate: (1) the impact of factors on the ability to use mobile money services and have accounts at financial intermediaries; (2) The impact of mobile money and having an account at a financial intermediary on the ability to use digital transactions. The data used in the study is from the World Bank survey in 2017 (The Global Findex Database) results for Vietnam, with a sample of 1,002 people.

According to Table 4 (column 1), the Logit regression result shows that the independent variables can explain 17.56\% of the variation of the dependent variables (likelihood of using mobile money service). The independent variables including account use at financial intermediaries and the income level are statistically significant at the $1 \%$, while the age variable is significant at $5 \%$. Specifically, the variable account_fin has a coefficient $>0$, which means that the use of accounts at financial intermediaries has a positive correlation with the probability of using mobile money services. The variable age has a coefficient $<0$, implying that age has a negative correlation with the probability of using mobile money. The variable inc_q has a coefficient $>0$, meaning that the higher the income, the more likely it is to use mobile money.

According to Table 4 (column 2), the Logit model shows that the independent variables can explain $18.89 \%$ of the variation of the dependent variables (bank account ownership). The independent variables including age, education level, income level, having payroll within 12 months and the use of mobile money have statistical significance at the $1 \%$ level, while the variable for borrowing money from financial institutions is significant $10 \%$. Specifically, the account_mob variable has a coefficient $>0$, which means that the use of mobile money can increase the likelihood of 
owning a bank account. The age variable has a positive coefficient, suggesting that the older the customer, the more likely she is to have a bank account.

Thus, compared to mobile money accounts, accounts at financial intermediaries may be more universal and necessary, especially for individuals who are older. The variables educ, rec_wage_payment and inc_q all have positive coefficients, indicating that more educated, employed individuals with higher real income are more likely to own a bank account. Finally, the variable borrow_fininst has a positive coefficient, consistent with the fact that borrowers will open an account at the lender to track payments as well as to disburse the loan.

Table 4. Logistic regression results with two dependent variables: account_mob \& account_fin

\begin{tabular}{lll}
\hline Variables & (1) account_mob & (2) account_fin \\
\hline female & 0.342 & -0.035 \\
\hline age & $(0.91)$ & $(-0.22)$ \\
\hline & $-0.039^{*}$ & $-0.016^{* *}$ \\
\hline educ & $(-2.00)$ & $(-3.18)$ \\
\hline & 0.177 & $1.336^{* * *}$ \\
\hline inc_q & $(0.54)$ & $(9.74)$ \\
\hline & $0.291^{*}$ & $0.176^{* *}$ \\
\hline borrow_fin & $(2.06)$ & $(3.06)$ \\
\hline & 0.384 & 0.368 \\
\hline utilitybill & $(0.90)$ & $(1.86)$ \\
\hline & -0.203 & 0.153 \\
\hline wage_payment & $(-0.41)$ & $(-0.72)$ \\
\hline & -0.429 & $0.433^{* *}$ \\
\hline account_fin & $(-1.01)$ & $(2.90)$ \\
\hline & $1.839^{* * *}$ & \\
\hline account_mob & $(3.56)$ & $1.782^{* * *}$ \\
\hline & & $(3.41)$ \\
\hline cons & & $-3.528^{* * *}$ \\
\hline & $-4.773^{* * *}$ & $(-6.90)$ \\
\hline
\end{tabular}

Note: account_mob: mobile money account; educ: educational level; inc_q: income group; borrow_fininst: borrow money from a financial institution; wage_payment: have received wages within the past 12 months; account_fin: using an account at a financial intermediary; govtrans_cash: receive government transfers / remittances, receiving 1 if in cash and 0 otherwise; dom_remit_cash_noncash: transfer money in cash, receiving 1 if money is not transferred in cash and 0 otherwise, debit_credit: whether the individual has a debit or credit card, 1 if yes, 0 if no; debit_credit_use: whether the individual has debit or credit card transactions, 1 if yes, 0 if no; delivery_int_cash: pay online, receiving 1 if payment is not in cash and 0 otherwise ; billpaid_cash: pay utility bill, receiving 1 if pay bill by cash and 0 if otherwise; wage_cash: get salary, receiving 1 if in cash and 0 otherwise. Numbers in parentheses are t-values.

Source: Author's calculation from research data

Table 5 provides logistic regression results that examine the factors that influence individuals' likelihood to choose non-cash transactions in Vietnam. Column (1) shows that the model is able to explain $14.86 \%$ of the dynamics of the dependent variable, and individuals with bank accounts will be less likely to receive cash payments from government. Column (2) shows that the model accounts for $41.17 \%$ of the variation of the dependent variable, and that individuals with higher education levels are more likely to receive wages in many forms other than cash. Owning mobile money accounts and financial intermediaries also facilitates the receipt of non-cash salary payments. Column (3) also shows 
that the possession of mobile wallet and bank accounts allows payment of utility bills by the internet, and the model explains $18.13 \%$ of the dependent variable fluctuation.

Column (4) shows that the older individuals are less likely to own a credit or debit card, this result may be due to the influence of the highly elderly individuals in the sample. In addition, individuals with high incomes and the need to pay utility bills tend to own more cards. Finally, individuals with accounts at financial intermediaries will also be more likely to own debit or credit cards. This model have a highly explanatory power (66.7\% of the variation of the dependent variable). Column (5) shows that individuals with a high level of education and a mobile money account are also more likely to use the card more often. Thus, the results in column (5) of table 5 and the results in table 4 imply a mutual rather than confrontational relationship of these two types of accounts. This result shows the opposite trend with African countries as documented in Fanta et al. (2016), in which the two types of accounts tend to replace each other.

Column (6) shows that individuals with mobile money accounts are prone to choose non-cash transfers, but individuals with financial intermediaries prefer to transfer money in cash. The model in column 6 explains $24.37 \%$ of the fluctuations in the variable for cash or non-cash transfers. Column (7) shows that for the payment of goods delivered to the recipient, individuals with mobile money accounts tend to choose to pay on the internet instead of cash at the time of delivery. Meanwhile, for individuals who have accounts at financial intermediaries, this behavior is not statistically significant. This model explains $27.86 \%$ of the choice of internet payment or cash payment for goods purchased.

Table 5. Logistic regression with dependent variable is the type of non-cash transactions

\begin{tabular}{|c|c|c|c|c|c|c|c|}
\hline & (1) & (2) & (3) & (4) & (5) & (6) & (7) \\
\hline Variables & govtrans & wage & billpaid & debitcredit & Debitcredit use & remit & delivery \\
\hline \multirow[t]{2}{*}{ female } & 0.240 & 0.342 & 0.271 & 0.305 & 0.175 & 0.015 & -1.44 \\
\hline & $(0.56)$ & $(0.99)$ & $(0.82)$ & $(1.11)$ & $(0.52)$ & $(0.04)$ & $(-1.83)$ \\
\hline \multirow[t]{2}{*}{ age } & 0.011 & 0.007 & -0.01 & $-0.059 * * *$ & -0.014 & -0.015 & 0.028 \\
\hline & $(0.87)$ & $(0.43)$ & $(-0.72)$ & $(-5.36)$ & $(-0.89)$ & $(-1.17)$ & $(0.61)$ \\
\hline \multirow[t]{2}{*}{ educ } & 0.417 & $-0.658^{*}$ & -0.315 & $0.398 *$ & $0.619 *$ & 0.459 & 0.455 \\
\hline & $(1.10)$ & $(-2.34)$ & $(-1.04)$ & $(2.05)$ & $(2.40)$ & $(1.53)$ & $(0.77)$ \\
\hline \multirow[t]{2}{*}{ inc_q } & -0.165 & -0.067 & 0.026 & $0.292 * *$ & -0.058 & 0.199 & 0.454 \\
\hline & $(-1.14)$ & $(-0.51)$ & $(0.20)$ & $(2.83)$ & $(-0.46)$ & $(1.42)$ & $(1.58)$ \\
\hline \multirow[t]{2}{*}{ borrow_fin } & 0.377 & -0.045 & 0.013 & 0.106 & -0.468 & 0.379 & 0.216 \\
\hline & $(0.63)$ & $(-0.11)$ & $(0.04)$ & $(0.34)$ & $(-1.19)$ & $(0.93)$ & $(0.32)$ \\
\hline \multirow[t]{2}{*}{ utilitybill } & 0.673 & 0.247 & 0.533 & $0.659^{*}$ & 0.609 & 0.541 & -0.537 \\
\hline & $(1.42)$ & $(0.50)$ & (1.41) & $(2.11)$ & (1.31) & $(1.38)$ & $(-0.77)$ \\
\hline \multirow[t]{2}{*}{ wage_payment } & 0.156 & -0.219 & -0.15 & 0.085 & -0.139 & -0.335 & 0.832 \\
\hline & $(0.34)$ & $(-0.61)$ & $(-0.53)$ & $(0.34)$ & $(-0.47)$ & $(-0.89)$ & (1.04) \\
\hline \multirow[t]{2}{*}{ account_mob } & -1.369 & $-2.911 * * *$ & $-1.363^{* *}$ & 1.477 & $2.849 * * *$ & $-1.446^{*}$ & $2.712 * * *$ \\
\hline & $(-1.11)$ & $(-4.11)$ & $(-2.86)$ & (1.93) & $(4.79)$ & $(-2.52)$ & (4.19) \\
\hline \multirow[t]{2}{*}{ account_fin } & $-1.696 * * *$ & $-3.744 * * *$ & $-2.259 * * *$ & $5.081 * * *$ & - & $2.131 * * *$ & 0.768 \\
\hline & $(-3.51)$ & $(-6.39)$ & $(-4.86)$ & $(15.87)$ & - & $(5.02)$ & $(0.75)$ \\
\hline \multirow[t]{2}{*}{ _cons } & -0.267 & $4.092 * *$ & $4.415 * *$ & $-3.987 * * *$ & $-2.844 *$ & -1.858 & -5.137 \\
\hline & $(-0.18)$ & $(2.63)$ & $(3.07)$ & $(-4.39)$ & $(-2.31)$ & $(-1.70)$ & $(-1.65)$ \\
\hline
\end{tabular}

Note: account_mob: mobile money account; educ: educational level; inc_q: income group; borrow_fininst: borrow money from a financial institution; wage_payment: have received wages within the past 12 months; account_fin: using an account at a financial intermediary; govtrans_cash: receive government transfers / remittances, receiving 1 if in cash and 0 otherwise; dom_remit_cash_noncash: transfer money in cash, receiving 1 if money is not transferred in cash and 0 otherwise, debit_credit: whether the individual has a debit or credit card, 1 if yes, 0 if no; debit_credit_use: whether the individual has debit or credit card transactions, 1 if yes, 0 if no; delivery_int_cash: pay 
online, receiving 1 if payment is not in cash and 0 otherwise; billpaid_cash: pay utility bill, receiving 1 if pay bill by cash and 0 if otherwise; wage_cash: get salary, receiving 1 if in cash and 0 otherwise. Numbers in parentheses are t-values.

\section{Conclusion and Implications}

This study provides an overview of the trends of mobile money accounts, financial inclusion and cashless transaction in Vietnam, and considers the factors that influence these trends. In general, the rates of using mobile money and accounts at financial intermediaries in Vietnam are still low, and other indicators suggest that non-cash transaction trends are low compared to middle and low income countries and compared to the world average. However, this opens up great opportunities for non-cash transactions to mushroom in Vietnam (due to the fact that there is still room for growth), along with the trend of promoting inclusive finance and e-commerce in the segment boom compared to other countries in the region and around the world.

The study also shows that mobile money and financial intermediation accounts are not mutually exclusive, but complementary. This is a positive trend, at least compared to the situation in some African countries. Mobile money accounts and financial intermediaries generally have a positive effect on the trend of non-cash transactions. The current problem is that the rates of using mobile money and accounts at financial intermediaries in Vietnam are quite limited compared to the common levels of other countries. To build a non-cash economy, it is necessary to continue to facilitate these forms to thrive through the development of updated legal frameworks, support for technologies that ensure speed and safety in non-cash transactions.

This study only uses cross-sectional data, so the variation across time is not available, and it is a single country study. Further studies could enrich the data by including more countries to examine whether there are differences in the above links across economies, or to build the panel data for Vietnamese observations. Also, researchers could analyze the impact of various aspects of mobile money such as mobile payment delivered by FinTech companies and innovative financial service providers on financial inclusion and digital payment transactions. As mentioned earlier, this study uses accounts at financial intermediaries to measure financial inclusion, other studies could analyze digital financial inclusion - digital access to, and the use of, formal financial services - to test the robustness of the results of this study.

\section{Acknowledgment}

This research is funded by University of Economics and Law, Vietnam National University Ho Chi Minh City, Vietnam.

\section{References}

Allen, F., Carletti, E., Cull, R., Qian, J., Senbet, L., \& Valenzuela, P. (2014). The African financial development and financial inclusion gaps. Journal of African Economies, 23(5), 614-642. https://doi.org/10.1093/jae/eju015

Andrianaivo, M., \& Kpodar, K. (2012). Mobile phones, financial inclusion, and growth. Review of Economics and Institutions, 3(2), 30. https://doi.org/10.5202/rei.v3i2.75

Asongu, S. A., Anyanwu, J. C., \& Tchamyou, V. S. (2017). Technology-driven information sharing and conditional financial development in Africa. Information Technology for Development, 1-30. https://doi.org/10.2139/ssrn.2722516

Barnes, S. J., \& Corbitt, B. (2003). Mobile banking: Concept and potential. International Journal of Mobile Communications, 1(3), 273-288. https://doi.org/10.1504/IJMC.2003.003494

Demirgüç-Kunt, A., Klapper, L. F., Singer, D., \& Van Oudheusden, P. (2015). The Global Findex Database 2014: measuring financial inclusion around the world. World Bank Policy Research Working Paper, No.7255. https://doi.org/10.1596/1813-9450-7255

Fanta, A. B., Mutsonziwa, K., Goosen, R., Emanuel, M., \& Kettles, N. (2016). The role of mobile money in financial inclusion in the SADC region. Evidence using Fin Scope surveys. Policy Research Paper No. 03/2016.

GSMA. (2015). State of the industry report: Mobile Money. GSMA, United Kingdom.

Hinson, R. E. (2011). Banking the poor: The role of mobiles. Journal of Financial Services Marketing, 15(4), 320-333. https://doi.org/10.1057/fsm.2010.29 
Honohan, P., \& Beck, T. (2007). Making finance work for Africa. World Bank Publications. https://doi.org/10.1596/978-0-8213-6909-8

Kanobe, F., Alexander, P. M., \& Bwalya, K. J. (2017). Policies, regulations and procedures and their effects on mobile money systems in Uganda. The Electronic Journal of Information Systems in Developing Countries, 83(1), 1-15. https://doi.org/10.1002/j.1681-4835.2017.tb00615.x

KPMG. (2011). Monetizing mobile: How banks are preserving their place in the payment value chain. KPMG International Cooperative. Retrieved from https://home.kpmg.com/ru/en/home/media/press-releases/2012/03/monetizing-mobile-how-banks-are-preserv ing-their-place-in-the ${ }^{-}$payment-value-chain.html

Maurer, B. (2012). Mobile money: Communication, consumption and change in the payments space. Journal of Development Studies, 48(5), 589-604. https://doi.org/10.1080/00220388.2011.621944

Merritt, C. (2011). Mobile money transfer services: The next phase in the evolution of person-to-person payments. Journal of Payments Strategy \& Systems, 5(2), 143-160.

Sihvonen, M. (2006). Ubiquitous financial services for developing countries. The Electronic Journal of Information Systems in Developing Countries, 28(1), 1-11. https://doi.org/10.1002/j.1681-4835.2006.tb00193.x

World Bank. (2018). The little data book on financial inclusion. 